\title{
Norms for two types of manipulability (graspability and functional usage), familiarity, and age of acquisition for 320 photographs of objects
}

\author{
J. P. SAlmon, P. A. McMullen, And J. H. Filliter \\ Dalhousie University, Halifax, Nova Scotia, Canada
}

\begin{abstract}
There is increasing interest in the role that manipulability plays in processing objects. To date, Magnié, Besson, Poncet, and Dolisi's (2003) manipulability ratings, based on the degree to which objects can be uniquely pantomimed, have been the reference point for many studies. However, these ratings do not fully capture some relevant dimensions of manipulability, including whether an object is graspable and the extent to which functional motor associations above and beyond graspability are present. To address this, we collected ratings of these dimensions, in addition to ratings of familiarity and age of acquisition (AoA), for a set of 320 black-and-white photographs of objects. Familiarity and AoA ratings were highly correlated with previously reported ratings of the same dimensions ( $r=.853, p<.001$, and $r=.771, p<.001$, respectively), validating the present norms. Grasping and functional use ratings, in contrast, were more moderately correlated with Magnié et al.'s pantomime manipulability ratings $(r=.507, p<.001)$. These results were taken as evidence that the new manipulability ratings collected in this research capture distinct aspects of object manipulability. The complete stimuli and norms from this study may be downloaded from http://brm.psychonomic-journals.org/content/supplemental.
\end{abstract}

There has been increasing interest in the role that manipulability and object action play in object recognition (where manipulability is defined as the extent to which an object can be picked up or grasped and then used). Yoon, Heinke, and Humphreys (2002) proposed a direct route from early visual (structural) descriptions to action that does not require the semantic system. This direct route parallels that from the input lexicon to the phonological name (naming) output and helps explain why participants are faster to name the word hammer than to name a picture of the hammer but faster to gesture at the picture than they are at the word. These two direct routes in Yoon et al.'s naming action model interact at the level of semantics, which may explain why manipulability influences object recognition (cf. Filliter, McMullen, \& Westwood, 2005; see also Humphreys, 2001).

Research on brain-damaged patients has also pointed to a role for manipulability in visual object recognition. Early work with individuals with visual object agnosia was focused on impairments in visual object recognition that were specific to the objects' living or nonliving category status (cf. Farah, McMullen, \& Meyer, 1991; Farah, Meyer, \& McMullen, 1996; Gaffan \& Heywood, 1993; Warrington \& Shallice, 1984). More recently, there has been interest in the notion that the relevant object dimension underlying this deficit may, in fact, be object manipulability (see Borgo \& Shallice, 2003; Humphreys \& Rid- doch, 2001). Wolk, Coslett, and Glosser (2005) were able to show that object manipulability can be an important predictor of a visual object agnosic's ability to identify objects, with the patients being more likely to accurately recognize highly manipulable objects. Some patients with visual agnosia retain the ability to gesture the functional use of objects and are termed optic aphasics. This supports the direct route to action proposed by Yoon et al. (2002). In a double dissociation, patients with apraxia are known to have deficits in functionally using objects but they retain the ability to identify those objects (Riddoch, Humphreys, \& Price, 1989).

A common reference point for manipulability ratings has been Magnié, Besson, Poncet, and Dolisi's (2003) ratings, which were based on the ability to unambiguously pantomime an object. Wolk et al. (2005) also proposed form-manipulation ratings based on the extent to which the form predicts how the object should be used. Magnié et al.'s ratings appear to suffer from face validity issues, because their ratings seem to be more about pantomiming than about manipulability (grasping and using objects). Wolk et al.'s ratings suffer from a low $n$ (the ratings for only a few items were published).

In the present research, we set out to collect ratings of other aspects of manipulability not captured by existing ratings for a set of 320 objects. The objects were chosen from a variety of categories, including animals, fruits,

J.P. Salmon, joshua.salmon@dal.ca or joshua.salmon@gmail.com 
vegetables, vehicles, tools, household appliances, and local landmarks. Familiarity and age of acquisition (AoA) ratings for each object were also collected, since these variables have been shown to influence object processing (Bates et al., 2003; Bonin, Peereman, Malardier, Méot, \& Chalard, 2003; Cuetos \& Alija, 2003; Pérez, 2007).

\section{Manipulability}

Presumably, a manipulability rating should capture some dimension of picking up and/or grasping an object. For example, Grèzes and Decety (2002) used objects that they described as being "capable of being grasped and manipulated by one hand" (p. 214). In Magnié et al.'s (2003) study, in which they collected object manipulability ratings, participants were asked, "Could you easily mime the action usually associated with this object so that any person looking at you doing this action could decide which object goes with this action?" (p. 524). This definition has a degree of face validity but leads to some unusual classifications of objects. For example, it is hard to pantomime the use of an apple in a way that is distinguishable from that of a pear, a peach, or many other edible objects. Thus, apples, peaches, and pears were rated as unmanipulable on Magnié et al.'s scale, even though they are quite manipulable if we define manipulability as the ability to pick an object up and grasp it with one or both hands (cf. Grèzes \& Decety, 2002). On the other hand, it is easy to pantomime sleeping in a bed, playing a piano, or riding a bicycle. As a result, bed, piano, and bicycle were rated as manipulable on Magnié et al.'s scale, even though these objects cannot be picked up. This classification of objects is counterintuitive: It is easy to pick up and grasp an apple, a peach, or a pear but close to impossible to do the same for a bed, a bicycle, or a piano. Therefore, there is a need for new manipulability ratings that capture the dimensionality of graspability as an aspect of manipulability. That is, a rating based on grasping instead of on pantomime (Manip1). Indeed, edible objects that can be grasped are likely to be important to the cognitive system of creatures that have evolved to retrieve food with their hands (apes and humans) and do so at very early stages of development (cf. Toledo \& Tudella, 2008; Witherington, 2005). Culham and Valyear (2006) indicated a unique neural pathway for grasping in the parietal (dorsal) cortex.

There are at least two ways to motorically interact with objects: grasping them and using them. The new ratings in this research are based on two manipulability rating scales that distinguish between these two types of motor responses. Wolk et al. (2005) came close to capturing the use or functional component of manipulability when they developed their form-manipulation ratings. In these ratings, they had participants rate "the degree to which the shape of the object implies how it should be used" (p. 135). However, their ratings still confounded the concepts of grasping and using. We propose a functional definition of manipulability (Manip2) that specifically incorporates the degree to which the motor scripts for using and those for picking objects up can be differentiated. In this way, the present definition describes functional motor actions in a way that is not dependent on the object's shape.

\section{Familiarity and AoA}

Like manipulability, object familiarity and AoA - the age at which a person acquired the name for an objectare also dimensions that influence object processing. The literature has shown that AoA influences object-naming time, such that object names learned at a younger age (low AoA) are associated with faster naming speeds than those learned later in life (e.g., Bonin et al., 2003; Cuetos \& Alija, 2003; Pérez, 2007). Object familiarity also influences object-naming time, with familiar objects being named more quickly than unfamiliar ones (cf. Bates et al., 2003). The cumulative frequency hypothesis suggested that AoA and object familiarity are really two labels for one effect (cf. Lewis, Gerhand, \& Ellis, 2001). However, recent research has shown distinct influences of these variables (cf. Dent, Johnston, \& Humphreys, 2008). This evidence suggests that object familiarity and AoA are separate constructs and should be treated as such. Given the importance of both of these dimensions in object naming, it was important for the present research to include ratings of both of these constructs for our new object set (in order to determine the effects of manipulability independent of these constructs). Ratings of these dimensions have also been provided in previous normed sets of objects (e.g., Morrison, Chappell, \& Ellis, 1997; Snodgrass \& Vanderwart, 1980).

\section{The Present Study}

In the present study, we collected ratings on object familiarity, AoA, and manipulability for over 320 blackand-white objects. The manipulability ratings were further divided into scales for grasping and functional use/ associations of an object. All of the participants rated all of the items on each scale, but the order of ratings was randomized, such that at least 18 participants saw the items for the first time for each scale. All of the ratings were collected from a university-age sample. The main goal of this research was to collect accurate, age-relevant ratings on a controlled set of objects to be used in future research. The objects were chosen a priori to maximize the likelihood that equal numbers would fall within each of the cells of a factorial $2 \times 2 \times 2$ design with high and low levels for each of the variables: familiarity, AoA, and manipulability.

Since familiarity and AoA naturally correlate, it was a challenge to generate items to populate some categories. For example, to fill the category of objects with low familiarity but acquired at a young age (low AoA), baby toys and other objects encountered in infancy were used. Also, to fill out the category of items with high familiarity, high and AoA and that were nonmanipulable, local university and town landmarks were used. ${ }^{1}$ For examples of item categories and where they were expected to be rated a priori, see Table 1. On this basis, a set of 320 objects, with approximately 40 objects in each design cell, were presented for rating.

The methodology used in this study differed somewhat from that used by previous researchers. A computer program was used to present objects on a large screen to a group of participants who rated objects by using a computer mouse to assign a rating on a computerized scale 
Table 1

Examples of Object Categories Expected to Fall

in Each Cell of the Factorial Design

\begin{tabular}{llll}
\hline & & \multicolumn{1}{c}{$\begin{array}{c}\text { Low AoA } \\
\text { (Acquired Early) }\end{array}$} & $\begin{array}{c}\text { High AoA } \\
\text { (Acquired Late) }\end{array}$ \\
\hline High Familiarity & $\begin{array}{l}\text { Manipulable } \\
\text { Nonmanipulable }\end{array}$ & $\begin{array}{l}\text { fruits, vegetables } \\
\text { furniture }\end{array}$ & $\begin{array}{l}\text { office/school supplies } \\
\text { local landmarks }\end{array}$ \\
& Manipulable & baby toys & musical instruments \\
& Nonmanipulable & common animals/pets & uncommon animals \\
\hline
\end{tabular}

Note-AoA, age of acquisition.

(each participant had his or her own computer). Other researchers have used an overhead projector to present exemplars and required participants to write their ratings with pen and paper (cf. Snodgrass \& Vanderwart, 1980). Also, in the present study, we used a practice set of eight items for each scale and anchors in the form of example objects for each extreme of a scale. For example, the object bed was provided as an example of a high-familiarity object, and submarine was used for low familiarity. In contrast, Snodgrass and Vanderwart used no explicit anchors and, instead, showed their participants 30 random items from their set before rating began. That is, they let the context of the first 30 items anchor the participants. In addition, in the present study, each participant rated all of the items on each of the scales. Snodgrass and Vanderwart, in contrast, had different groups rate each of their scales/tasks. In spite of these methodological differences, it was hypothesized that the ratings collected in the present study would not differ significantly from previous ratings where identical definitions for the parameters were employed. Specifically, in the present design, we used the same familiarity definition and 5-point scale as did Snodgrass and Vanderwart and the same $A o A$ definition and 7-point scale as did Morrison et al. (1997). For these reasons, it was expected that our ratings on these scales would correlate significantly with those previously published for overlapping objects. The manipulability ratings, on the other hand, were compared with ratings by Magnié et al. (2003) and Wolk et al. (2005).

\section{METHOD}

\section{Participants}

Fifty-seven undergraduate students (13 males), ranging in age from 18 to 29 years $(M=19.52$ years, $S D=2.30)$, rated all 320 pictures on all three rating scales. Most of the participants were right-handed (7 left-handed and 2 ambidextrous). All of them spoke English as their first language. All of them had normal or correctedto-normal vision. The participants were randomly assigned to one of three groups: (1) those who rated familiarity first $(n=20)$, (2) those who rated AoA first $(n=18)$, and (3) those who rated manipulability first $(n=19)$.

\section{Materials}

Stimuli. A set of 320 objects was chosen, such that approximately equal numbers would be assigned high and low ratings on each of the three rating scales. The object set was generated on the basis of the experimenters' predictions about classifications (e.g., baby rattle should score highly on the manipulability rating) and object ratings from previous studies (such as those by Snodgrass \& Vanderwart [1980], for familiarity). The objects were also chosen on the basis of the ease with which unambiguous photographs could be obtained (for example, a picture of the sun without the sky and clouds would look like just a circle). For example photographs, see Appendix A; photographs of all of the images can be found in the online supplemental materials. ${ }^{2}$

Each picture was cropped and shown in grayscale on a white background. The majority of the pictures were chosen from the Hemera CD photo set. However, some (particularly the Halifax, Nova Scotia, landmarks) were produced by the experimenters, using a digital camera. Some were also taken from online free-use photography Web sites, and a few were taken from the World Wide Web (with permission). All of the images were edited in Photoshop or GIMP, a freely licensed photo editing software (www.gimp.org). All of the images were saved as .BMP files and varied in size up to a maximum of $300 \times 300$ pixels. During rating sessions, the images were viewed at an unrestrained distance, ranging from 140 to $70 \mathrm{~cm}$ (two rows), resulting in visual angles of $6.1^{\circ}-12.2^{\circ}$ (subtended angle).

Rating scales. Ratings on three dimensions were obtained: familiarity, AoA, and manipulability. Manipulability was further divided into two subscales that were rated at the same time. The familiarity and AoA scales were rated on definitions consistent with those used in previous research (Morrison et al., 1997; Snodgrass \& Vanderwart, 1980). The definitions of manipulability employed, however, were unique to the present study and less consistent with those used in previous research (e.g., Magnié et al., 2003). Each scale was assigned two anchor images that exemplified strong high and low ratings on the dimension being evaluated.

The familiarity ratings were preceded by the following instructions:

For each object you see on the screen, please give it a rating on the familiarity scale. Rate your familiarity with the object according to how usual or unusual the object is in your realm of experience. That is, please rate your familiarity with the object or the degree to which you come into contact with or think about the concept on a day-to-day basis.

Familiarity was rated on a 5-point Likert scale (5, high familiarity; 1, low familiarity). For anchors, bed was used as an example of an item that would score high (5) on familiarity, and submarine was used as an example of an item that would score low (1) on familiarity.

AoA ratings were preceded by the following instructions:

For each object you see on the screen, please give it a rating on the age of acquisition scale. That is, please rate the object according to the age at which you think you likely learned the name for that object. Of course, it is impossible to remember exactly when you acquired the vocabulary, but please take your best educated guess.

AoA was rated on a 7-point scale and divided into ranges of 2 years ( $1,0-2$ years; 2, 3-4 years; $3,5-6$ years; $4,7-8$ years; 5 , $9-10$ years; $6,11-12$ years; $7,>13$ years $)$. For anchors, ball was used as an example of an item that was acquired early $(0-2$ years old, 1 on the scale), and iPod was used as an example of an item acquired late ( $>13$ years old, 7 on the scale). 
The participants rated items on manipulability twice, and the instructions for the first manipulability rating (Manip1) were "On the first scale, please rate the manipulability of the object according to how easy it is to grasp and use the object with one hand."

After the examples, the instructions were repeated as "First scale: Rate the manipulability of the object (the degree to which you can pick up and use) along a 5-point scale."

For anchors, rhinoceros was used as an example of an item that would score low (1) on the first manipulability scale, and spoon was used as an example of an item that would score high (5) on the first manipulability scale.

The rating on the second manipulability (Manip2) scale was contingent on the first rating, and the instructions read

On the second scale, for the objects that you just rated 3 or higher on the first scale, we would like you to provide a second rating on a different scale. Now, please rate the extent to which the hand movements that you make to use the object differ from the hand movements that you make to pick it up. If the two movements are very different, give it a high score ( 5 on the second manipulability rating); if the two movements are similar or identical, give it a low score ( 1 on the second manipulability rating).

After the examples, the instructions were repeated as "Second scale: Rate the extent to which the hand movements that you make to use the object differ from the hand movements that you make to pick it up along a 5-point scale."

For anchors, apple was used as an example of an item that would score low (1) on the second manipulability scale, and calculator was used as an example of an item that would score high (5) on the second manipulability scale.

Equipment. Each participant was assigned his or her own Mac OSX (700-MHz PowerPC G4) computer connected to the Internet. This allowed them to connect to the Opinio Survey Software on our local server, which was used to record their ratings for each picture. The survey software was set up so that each rating scale had its own Web address, where the scale, presented with anchors for each item, could be accessed. The software did not show the pictures or names of the objects to be rated. The pictures were presented on a screen using a projector controlled by a laptop. MATLAB (The MathWorks, Natick, MA) was used on the laptop to control the rate of picture presentation. The laptop was a Dell dual processor Windows XP machine. All of the participants were angled so that they would have a good view of the presentation screen from their computer station.

\section{Procedure}

The participants were tested in small groups of 1-7 individuals (average group size $=3.24$ ). Each group was assigned to one of three orders: FMA (familiarity, manipulability, then AoA), MAF (manipulability, AoA, then familiarity), or AFM (AoA, familiarity, then manipulability). These three orders were chosen to ensure that each scale was rated first one third of the time and that each scale was rated in all positions.

After informed consent was obtained, each participant was assigned to a computer. The participants were then handed instructions (on a single page for each participant) for the first rating scale, which the experimenter read out loud to the group. Once the instructions were understood and the participants were given a chance to ask questions, the group began with eight practice trials for the first rating scale. All of the pictures were shown to all of the participants at the same time on a screen at the front of the room. The picture presentation program allowed for pausing, going backward, skipping items, slowing down and speeding up presentation rate. Thus, if any participants missed an item, they could raise their hand and the experimenter would go back to the item that they had missed. During presentation, each picture was paired with a number that appeared both before presentation of the object and in the lower left corner of the screen while the picture was being presented. Furthermore, to simplify the rating process for the participants and to help keep them motivated, the experimenter read the number of each object aloud. In addition, a tone was played before each item appeared in order to alert both the participants and the experimenter that the picture on the overhead screen had changed (Figure 1).

After the practice items (eight photos) were rated, the experimenter reminded the group of the definition to be used to rate the items, answered any questions, and then began the first block of 320 object ratings. The items were randomized by the presentation computer prior to presentation. In this way, once the experiment began, the experimenter could go back to Item 12 , for example, and it would always be the same item/picture for that block. However, once the program was reloaded for a new block, the items were rerandomized. Small breaks were scheduled every 50 items. The only differences between the practice and full runs were that we used a different set of pictures in the full run, and it began with a slightly faster presentation rate (the objects were shown for a shorter duration).

The timing of the pictures was further modified on the basis of the scale that was currently being rated. The participants found familiarity to be the easiest scale to apply, and thus, the presentation rate for familiarity began at the fastest speed ( $3 \mathrm{sec}$ per picture). The manipulability scale required two ratings, making it the most complex, so the pictures remained on screen for a longer duration for this rating scale $(6 \mathrm{sec})$. For AoA ratings, the length of picture presentation began at $4 \mathrm{sec}$. Since the groups differed in the length of time that they required to rate the items, the option to speed up or slow down presentation time was built into the program used to project the items, and if the participants indicated that they found the presentation rate too slow or too fast, the experimenter could change the speed of the program (in 0.25 -sec increments). Speed decisions were made by the group during the brief breaks, every 50 items.

Once the participants had finished rating the set of 320 objects on the first scale, they were asked to provide demographic information about themselves (including their age, gender, and handedness) and then to submit their data. When the participants hit the submit button, the data was transferred to a central database, with a time stamp that was later synchronized with the list of items presented to the participants. The experimenter then collected the instruction pages for the first scale and handed out the instruction pages for the second scale. The participants were then read the new instructions, participated in a practice block for the new scale, and then began rating the 320 objects on the new scale. Finally, the third rating scale was completed following the same procedure. Between each new rating scale, longer breaks of approximately $3-5 \mathrm{~min}$ were allowed. Once all three rating scales were complete, the participants were debriefed. The entire experiment took approximately $2 \mathrm{~h}$ to complete.

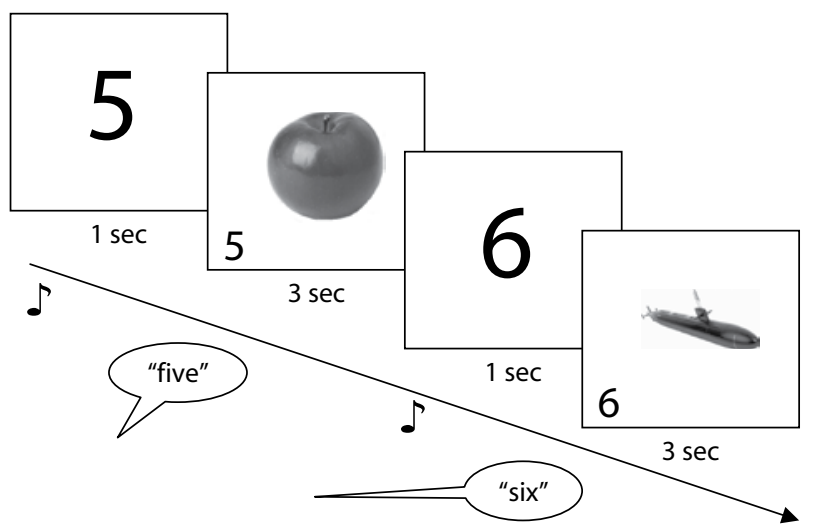

Figure 1. An example of two trials during the rating experiment. $\delta$ indicates where a warning tone was played to alert the participants (and the experimenter) that a new trial was about to start. Words in the bubbles indicate numbers being said by the experimenter. 
Specifically, the familiarity, AoA, and manipulability blocks lasted approximately 22,30 , and $45 \mathrm{~min}$, respectively.

\section{RESULTS}

\section{Summary}

The main analyses were correlations between the present ratings and ratings collected on the same items by previous researchers. These results are presented in detail below. To summarize, both familiarity and AoA correlations between our measures and previously published ratings were quite high $(r=.853, p<.001$, and $r=.771$, $p<.001$, respectively). Only for manipulability were the present ratings not strongly correlated with the previous ratings by Magnié et al. $(2003)(r=.507, p<.001)$ and were not correlated at all with the ratings by Wolk et al. (2005) $(r=-.126, p=.419)$. However, a low or absent correlation was expected for the manipulability ratings, because the definition of manipulability used to obtain the ratings in the present study was meant to capture a novel dimension of this construct not captured in previous research (cf. Magnié et al., 2003; Wolk et al., 2005).

Intercorrelations between our participants' ratings for the same objects across scales were also assessed. High correlations would indicate that two rating scales were being used in a similar way by the participants. Since the items/pictures were chosen to range across all categories of familiarity, AoA, and manipulability, it was predicted that the correlations should be low or nonexistent. For example, for the objects rated as highly familiar, equal numbers of them should have been rated as being high and low on AoA. As was predicted, most of our rating scales were not correlated with each other. The largest correlation was a weak one $(r=.297, p<.001)$ between AoA and our second manipulability scale (for the rest of these correlations, see Tables 2-6).

Finally, the participants in the three ratings orders (FMA, AFM, and MAF) were considered separately in an exploratory time analysis. That is, familiarity ratings from the participants in the FMA order (familiarity first) were compared with those from the AFM (familiarity second) and MAF (familiarity third) orders. High correlations on all scales (range: $r=.914-.991, p$ s $<.001$ ) indicated that all groups used the scales in an equivalent way. However, there was some drift in the mean for each of the scales. Since this analysis was not germane to the main objective of this article, it is excluded from the main Results section. ${ }^{3}$ In addition, it was decided that the main analyses should be focused on ratings for the items that the participants rated for the first time (familiarity from the FMA group, AoA from the AFM group, and manipulability from the MAF group), since these ratings were the most consistent with the ratings collected in previous research. However, for comparison, the overall ratings (collapsed across time for all of the participants) are also included in Appendix B. For the ratings at other times, as well as the categories for each object, please refer to the supplementary materials, available online.

\section{Familiarity Ratings/Norms}

Two participants were eliminated from the analysis of familiarity, because they arrived late for the study and had missed the full instructions on how to properly use the familiarity rating scale. Of the remaining 55 participants, 18 rated familiarity as their first scale (Time 1), 18 as their second (Time 2), and 19 as their third scale (Time 3 ). The familiarity ratings (at Time 1 ) were compared with those collected on the same objects in previous studies. Specifically, our ratings were further compared with the familiarity ratings collected by Snodgrass and Vanderwart (1980) and Morrison et al. (1997). With 190 and 184 items being compared, respectively, our ratings correlated highly $(r=.853, p<.001$, and $r=.825, p<$ .001 ; see Table 2). Therefore, despite some methodological differences, the familiarity ratings generated in the present study were similar to those obtained in previous research for the approximately 190 items in common. Additionally, the correlation for these items on familiarity between the Morrison et al. and Snodgrass and Vanderwart ratings was $r=.865, p<.001$ (not noticeably different from the present correlations).

\section{AoA Ratings/Norms}

The ratings from 57 participants were used to construct norms for AoA. Eighteen rated AoA as their first scale (Time 1), 19 as their second (Time 2), and 20 as their third scale (Time 3). The participants rating AoA at Time 1 were the same participants who rated familiarity at Time 2 . The AoA ratings (from Time 1) were compared with those collected on the same objects in previous studies. The present ratings were compared with those of Morrison et al. (1997), who derived norms by both testing the vocabulary of (British) children (objective) and having adults retroactively self-report AoA (subjective). Morrison et al. found objective and subjective correlations to be as high as $r=$ .759 , supporting the idea that subjective reports of AoA are accurate estimates of actual AoA (p. 542). The present ratings were also highly correlated with Morrison et al.'s ratings for the $n=184$ items in common $(r=.771, p<$ $.001)$. The present ratings were also compared with Gilhooly and Logie's (1980) ratings, which were collected from self-reports of AoA to words (not pictures). In this case, not as many items could be compared $(n=83)$, but the correlation was still strong $(r=.719, p<.001)$. Thus,

Table 2

Familiarity Norm Correlations Across Studies

\begin{tabular}{lcc}
\hline \multicolumn{1}{c}{ Familiarity Ratings } & Snodgrass \& Vanderwart (1980) & Morrison et al. (1997) \\
\hline Present study (Time 1) & $.853^{* * *}$ & $.825^{* * *}$ \\
Snodgrass \& Vanderwart (1980) & - & $.865^{* * *}$ \\
${ }^{* * *} p<.001$. & &
\end{tabular}


Table 3

Age of Acquisition (AoA) Norm Correlations Across Studies

\begin{tabular}{lcc}
\hline \multicolumn{1}{c}{ AoA Ratings } & \multicolumn{1}{c}{ Morrison et al. (1997) } & Gilhooly \& Logie (1980) \\
\hline Present study (Time 1) & $.771^{* * * a}$ a & $.719^{* * * \mathrm{~b}}$ \\
Morrison et al. (1997) & - & $.748^{* * * \mathrm{c}}$ \\
\hline${ }^{* * *} p<.001 . \quad$ aBased on $n=184$. & bBased on $n=83$. & cBased on $n=61$.
\end{tabular}

despite minor methodological differences (e.g., using a computer to rate objects instead of pen and paper), our ratings were highly correlated with those of previous studies, thus validating the present ratings (see Table 3 ).

\section{Manipulability Ratings/Norms}

Although the familiarity and AoA ratings were useful as validations of the present methodology, it was the manipulability ratings that were of most interest. Again, the ratings from 57 participants were used to construct the norms for manipulability. Nineteen participants rated manipulability as their first scale (Time 1), 20 as their second (Time 2), and 18 as their third scale (Time 3 ). The participants rating manipulability at Time 1 were the same participants who rated familiarity at Time 3 .

All of the items were rated on the first manipulability scale (Manip1), but only the items considered to be manipulable on the first scale ( $>3$ as rated by the participants) were rated on the second (functional) manipulability scale (Manip2). As a result, some borderline-manipulable items (e.g., cat, chair, frog, wheel, sewing machine) were rated on the second manipulability scale by some, but not all, of the participants. To adjust for this low sample $(n)$ problem, only the items that the majority $(>50 \%)$ of the participants labeled as manipulable according to the first scale were considered to have valid functional manipulability scores. The result was 178 items (out of 320) with valid functional manipulability ratings.

Our manipulability ratings (from Time 1) were correlated to Magnié et al.'s (2003) norms. Recall that Magnié et al.'s definition revolved around the extent to which an item could be pantomimed unambiguously. The present definition (for the first scale), in contrast to that of Magnié et al., related to how easy it was to grasp and use the object with one hand. Thus, given the difference in definitions, categorical differences were expected between Magnié et al.'s and the present manipulability ratings. As was anticipated, the present manipulability scales correlated only moderately with those of Magnié et al.'s, with correlations of $r=.507$ for Manip1 and $r=.459$ for Manip2 $(p$ s $<$ .001) (see Table 4).

Wolk et al.'s (2005) form-manipulation ratings did not correlate with either the present or Magnié et al.'s (2003) ratings (Manip1, $r=-.126, p=.419$; Manip2, $r=.152$, $p=.375$; Magnié et al., $r=.254, p=.109$ ). However, Wolk et al. provided form-manipulation ratings for only a handful of items (62 items), so power was restricted in this case. Furthermore, the two present manipulability scales (Manip1 and Manip2) did not correlate significantly with each other $(r=-.012, p=.875)$, indicating that they were indeed measures of two different dimensions of manipulability.

To further illustrate the differences between the present ratings and those of Magnié et al. (2003), a comparison between the way in which a number of items were rated on the present scale (Manip1) and the way in which they were rated in Magnié et al. (MM Index) was done. Magnié et al. divided items into four categories on the basis of their ratings: (1) strongly manipulable, (2) weakly manipulable, (3) weakly unmanipulable, and (4) strongly unmanipulable. Table 5 shows examples of items that fell into each category on their rating (MM Index) scheme (rows) and where they fit on the present (Manip1) scheme (columns). The items for which the two scales agreed are underlined. The items for which the scales disagreed are depicted in bold. For example, in both scales, the following items were considered to be manipulable: cigarette, hammer, boot, mitten, and ruler. However, in Magnié et al.'s pantomime scale, the following items were also considered to be manipulable: bicycle, car, swing, and cow-whereas these items were rated as nonmanipulable using the present definition. In both scales, the following were aligned in their ratings for manipulability: train, cloud, chicken (live), moon, eagle, and elephant. However, in Magnié et al.'s pantomime scale, the following were also considered to be unmanipulable: pear, garbage can, celery, strawberry, and leaf. These items were considered manipulable by

Table 4

Manipulability Correlations to Magnié et al.'s (2003) Ratings

\begin{tabular}{|c|c|c|c|}
\hline $\begin{array}{l}\text { Manipulability } \\
\text { Ratings }\end{array}$ & Manip2 & $\begin{array}{c}\text { Magnié et al.'s (2003) } \\
\text { MM Index }\end{array}$ & $\begin{array}{l}\text { Wolk et al.'s (2005) } \\
\text { Form-Manipulation } \\
\text { Ratings }\end{array}$ \\
\hline a. Present Manip1 & -.012 (n.s.) $)^{\mathrm{a}}$ & $.507^{* * * a}$ & -.126 (n.s.) $)^{b}$ \\
\hline b. Present Manip2 & - & $.459^{* * * a}$ & .152 (n.s.) ${ }^{b}$ \\
\hline c. Magnié et al.'s MM Index & & - & 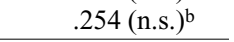 \\
\hline \multicolumn{4}{|c|}{$\begin{array}{l}\text { Note-Manip1, the first manipulation rating scale in the present study, based on the ability to } \\
\text { grasp the object; Manip2, the second manipulation rating scale in the present study, based on } \\
\text { functional usage. }{ }^{* * *} p<.001 \text {. aSmallest } n=178 \text {. bFor these correlations, } n \text { was as low } \\
\text { as } 36-43 \text { items. }\end{array}$} \\
\hline
\end{tabular}


Table 5

Differences Between the Present and Magnié et al.'s (2003)

Ratings on Manipulability

\begin{tabular}{cll}
\hline & \multicolumn{2}{c}{ Present Ratings } \\
\cline { 2 - 3 } Magnié et al.'s (2003) Ratings & \multicolumn{1}{c}{ Manipulable } & \multicolumn{1}{c}{ Nonmanipulable } \\
\hline Strongly manipulable & cigarette, hammer & bicycle, car \\
Weakly manipulable & boot, mitten, ruler & swing, cow \\
Weakly unmanipulable & pear, garbage can & train, cloud, chicken \\
Strongly unmanipulable & celery, strawberry, leaf & moon, eagle, elephant \\
\hline
\end{tabular}

Note-Columns show the present classification (manipulable, nonmanipulable). Rows show Magnié et al.'s (2003) classification (MM Index). Items in bold indicate objects classified differently; underlined objects represent those classified similarly.

the participants using the present (Manip1) definition of manipulability.

\section{Intercorrelations Between Rating Scales}

The overlap between each of the ratings given for objects in the present experiment was considered. As would be expected, familiarity was correlated with AoA, but this correlation was not very large $(r=-.120, p<.05)$. The first manipulability scale was weakly correlated with familiarity $(r=.129, p<.05)$ but not with AoA $(r=-.049$, $p=.379$ ); familiar objects tended to be graspable. The second functional manipulability rating, on the other hand, was weakly correlated with AoA $(r=.297, p<.001)$ but not with familiarity $(r=.06, p=.934)$; objects with motor associations tended to be acquired later in life. However, these correlations were quite weak, and generalizations are likely unwarranted. As was stated above, the two manipulability ratings were not significantly correlated with each other $(r=-.012, p=.875)$. The low intercorrelations between all of these scales were taken as a sign that each scale did indeed capture an independent dimension of the data set. See Table 6 for all of these correlations.

\section{DISCUSSION}

These two new ratings of manipulability reflect two recognized motor associations-the ability to grasp (Manip1) and functional usage (Manip2) - that we believe are not well captured by the existing ratings of Magnié et al. (2003) and Wolk et al. (2005). Magnié et al.'s ratings, based on the ability to uniquely pantomime an associated action, suffer from a lack of face validity. Their scale captures whether or not there are distinct motor associations for an object. However, it certainly does not clearly cap- ture the grasping element of manipulability. Wolk et al.'s form-manipulation ratings, based on the extent that form predicts how an object should be used, captures both grasping and functional use in a single scale, but it is not clear which dimension is more strongly captured by Wolk et al.'s definition; the two are confounded. Wolk et al.'s form-manipulation ratings are also (to our knowledge) available for only a small set of items. Because of these issues with previous manipulability ratings, we feel that the present ratings represent an important addition to the literature.

Specifically, we feel that the present manipulability ratings are based on a more intuitive definition of manipulability than that provided by the pantomime ratings of Magnié et al. (2003). For example, we believe that celery, pears, and strawberries should be considered manipulable/ graspable objects (as they were on the present scales), since they are regularly picked up with use; however, these items were rated as unmanipulable on Magnié et al.'s scale. We also feel that the present two ratings for manipulability were able to separate out the grasping (Manip1) and functional usage (Manip2) dimensions of manipulability, whereas these two dimensions were confounded in Wolk et al.'s (2005) form-manipulation ratings. Obviously, there were some similarities. For example, the correlation between the present manipulability scales and Magnié et al.'s was moderate $(r=.459$ or $r=.507)$, suggesting that these dimensions do indeed partially overlap. For Wolk et al.'s ratings, the correlations with the present ones were not significant, but this may have been constrained by the fewer ratings available (smaller $n$ ). Finally, the present manipulability ratings (Manip1 and Manip2) were found to be not correlated with each other $(r=-.012, p=.875)$, which supports our assertion that these two measures represent

Table 6

Interitem Correlations of Familiarity, AoA, and Manipulability

\begin{tabular}{lccc}
\hline & Familiarity & Manip1 & Manip2 \\
\hline AoA & $-.120^{*}$ & -.049 (n.s.) & $.297^{* * *}$ \\
Familiarity & - & $.129^{*}$ & .006 (n.s.) \\
Manip1 & & - & -.012 (n.s.)
\end{tabular}

Note $-n=320$ for all items except those correlated with Manip2 $(n=$ 178 in this case). Manip1, the first manipulation rating scale in the present study, based on the ability to grasp the object; Manip2, the second manipulation rating scale in the present study, based on functional usage. ${ }^{*} p<.05 .{ }^{* * *} p<.001$. 
independent dimensions of manipulability. Future research will be necessary to see which dimensions of manipulability are most useful in different contexts.

As for the new familiarity and AoA ratings collected, we feel that these ratings are as valid as those collected by previous research. That is, despite some methodological differences in the present study, the pattern of results obtained for familiarity and AoA were highly correlated with the results obtained in previous research $(r=.719-.853$, $p$ s < .001). These high correlations for both familiarity and AoA suggests that the methodological changes in the present study (i.e., using a computer instead of pen and paper and using explicit anchors and examples instead of anchoring through exposure) did not adversely impact the quality of the present ratings.

In conclusion, the manipulability norms collected in the present research are a valuable addition to the literature. They represent a dimension distinctly different from those reported and used by others (e.g., Magnié et al., 2003; Wolk et al., 2005). In many ways, these new definitions are more intuitive (i.e., a pear is considered manipulable). They are also more consistent with how other researchers have used manipulability (cf. Grèzes \& Decety, 2002). These ratings should have implications for future research of object recognition models that include action (cf. Yoon et al., 2002), as well as for research into the neuropsychology of agnosia and apraxia.

\section{AUTHOR NOTE}

Special thanks to Heather Schellinck for allowing us to use her lab for data collection and for donating so much of her time and resources to this project. Thanks to Bradley Frankland for his statistical advice throughout this project. Also, thanks to all the lab volunteers who helped with various aspects of this research (Kristy Newell, Anna Johannesson, Calvin Simmons, Janet Logan, and Sarah Hutchings). Thanks also to the rest of the team (Heath Matheson and Michelle Tougas). Correspondence concerning this article should be addressed to J. P. Salmon, Department of Psychology, Dalhousie University, Halifax, NS, B3H 3J5 Canada (e-mail: joshua.salmon@dal.ca or joshua.salmon@ gmail.com).

\section{REFERENCES}

Bates, E., D’ Amico, S., Jacobsen, T., Székely, A., Andonova, E., DeVESCOVI, A., ET AL. (2003). Timed picture naming in seven languages. Psychonomic Bulletin \& Review, 10, 344-380.

Bonin, P., Peereman, R., Malardier, N., Méot, A., \& Chalard, M. (2003). A new set of 299 pictures for psycholinguistic studies: French norms for name agreement, image agreement, conceptual familiarity, visual complexity, image variability, age of acquisition, and naming latencies. Behavior Research Methods, Instruments, \& Computers, 35, 158-167.

Borgo, F., \& Shallice, T. (2003). Category specificity and feature knowledge: Evidence from new sensory-quality categories. Cognitive Neuropsychology, 20, 327-353. doi:10.1080/02643290244000310

Cuetos, F., \& Alija, M. (2003). Normative data and naming times for action pictures. Behavior Research Methods, Instruments, \& Computers, 35, 168-177.

Culham, J. C., \& Valyear, K. F. (2006). Human parietal cortex in action. Current Opinion in Neurobiology, 16, 205-212. doi:10.1016/j .conb.2006.03.005

Dent, K., Johnston, R. A., \& Humphreys, G. W. (2008). Age of acquisition and word frequency effects in picture naming: A dual-task investigation. Journal of Experimental Psychology: Learning, Memory, \& Cognition, 34, 282-301. doi:10.1016/j.actpsy.2008.05.005
Farah, M. J., McMullen, P. A., \& Meyer, M. M. (1991). Can recognition of living things be selectively impaired? Neuropsychologia, 29, 185-193. doi:10.1016/0028-3932(91)90020-9

Farah, M. J., Meyer, M. M., \& McMullen, P. A. (1996). The living/ nonliving dissociation is not an artifact: Giving an a priori implausible hypothesis a strong test. Cognitive Neuropsychology, 13, 137-154. doi:10.1080/026432996382097

Filliter, J. H., McMullen, P. A., \& Westwood, D. (2005). Manipulability and living/non-living category effects on object recognition. Brain \& Cognition, 57, 61-65. doi:10.1016/j.bandc.2004.08.022

GafFan, D., \& HeYwood, C. A. (1993). A spurious category-specific visual agnosia for living things in normal human and nonhuman primates. Journal of Cognitive Neuroscience, 5, 118-128. doi:10.1162/ jocn.1993.5.1.118

Gilhooly, K. J., \& Logie, R. H. (1980). Age-of-acquisition, imagery, concreteness, familiarity, and ambiguity measures for 1,944 words. Behavior Research Methods \& Instrumentation, 12, 395-427.

GrÈzes, J., \& Decety, J. (2002). Does visual perception of object afford action? Evidence from a neuroimaging study. Neuropsychologia, 40, 212-222.

Humphreys, G. W. (2001). Objects, affordances . . a action! The Psychologist, 14, 408-412.

HumphreYs, G. W., \& RidDoch, M. J. (2001). Detection by action: Neuropsychological evidence for action-defined templates in search. Nature Neuroscience, 4, 84-88. doi:10.1038/82940

Lewis, M. B., Gerhand, S., \& Ellis, H. D. (2001). Reevaluating age of acquisition effects: Are they simply cumulative frequency effects? Cognition, 78, 189-205. doi:10.1016/S0010-0277(00)00117-7

Magnié, M. N., Besson, M., Poncet, M., \& Dolisi, C. (2003). The Snodgrass and Vanderwart set revisited: Norms for object manipulability and for pictorial ambiguity of objects, chimeric objects, and nonobjects. Journal of Clinical \& Experimental Neuropsychology, 25, 521-560. doi:10.1076/jcen.25.4.521.13873

Morrison, C. M., Chappell, T. D., \& Ellis, A. W. (1997). Age of acquisition norms for a large set of object names and their relation to adult estimates and other variables. Quarterly Journal of Experimental Psychology, 50A, 528-559. doi:10.1080/027249897392017

Pérez, M. A. (2007). Age of acquisition persists as the main factor in picture naming when cumulative word frequency and frequency trajectory are controlled. Quarterly Journal of Experimental Psychology, 60, 32-42.

Riddoch, M. J., Humphreys, G. W., \& Price, C. J. (1989). Routes to action: Evidence from apraxia. Cognitive Neuropsychology, 6, 437-454. doi:10.1080/02643298908253424

Snodgrass, J. G., \& Vanderwart, M. (1980). A standardized set of 260 pictures: Norms for name agreement, image agreement, familiarity and visual complexity. Journal of Experimental Psychology: Human Learning \& Memory, 6, 174-215. doi:10.1037/ 0278-7393.6.2.174

Toledo, A. M., \& Tudella, E. (2008). The development of reaching behavior in low-risk preterm infants. Infant Behavior \& Development, 31, 398-407. doi:10.1016/j.infbeh.2007.12.006

Warrington, E. K., \& Shallice, T. (1984). Category specific semantic impairments. Brain, 107, 829-854.

Witherington, D. C. (2005). The development of prospective grasping control between 5 and 7 months: A longitudinal study. Infancy, 7, 143161. doi:10.1207/s15327078in0702_2

Wolk, D. A., Coslett, H. B., \& Glosser, G. (2005). The role of sensory-motor information in object recognition: Evidence from the category-specific visual agnosia. Brain \& Language, 94, 131-146. doi:10.1016/j.bandl.2004.10.015

Yoon, E. Y., Heinke, D., \& Humphreys, G. W. (2002). Modeling direct perceptual constraints on action selection: The Naming and Action Model (NAM). Visual Cognition, 9, 615-661. doi: $10.1080 / 13506280143000601$

\section{NOTES}

1. Such local landmarks, of course, would be relevant only to local research. Other researchers wanting to make full use of this database would have to replace those items with equivalent local landmarks in their own area. 
2. For the complete set of pictures, refer to the Psychonomic Society's online supplemental materials for this article or to the second author's Web site, at http://myweb.dal.ca/mcmullen.

3 . For more information about these analyses, please contact the authors.

\section{SUPPLEMENTAL MATERIALS}

The complete set of stimuli and norms discussed in this article may be downloaded from http://brm.psychonomic-journals.org/content/ supplemental.

APPENDIXA

Examples of Items/Pictures Used in the Present Design

High familiarity Manipulable
Low familiarity
Manipulable
(Acquired Early)
Nonmanipulable


APPENDIX B

Mean Ratings and Standard Deviations (SDs) on Each Scale for Each Object

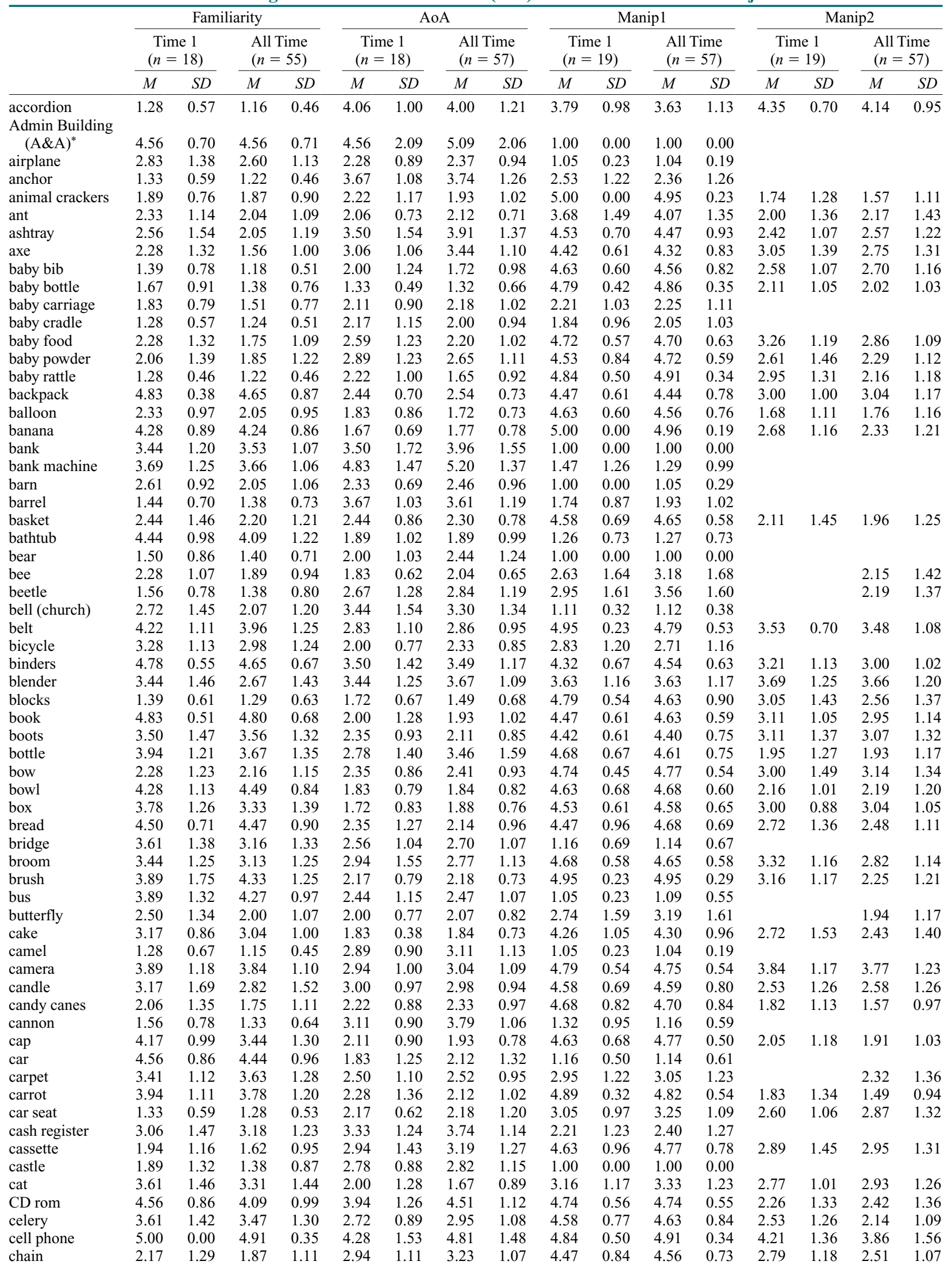


APPENDIX B (Continued)

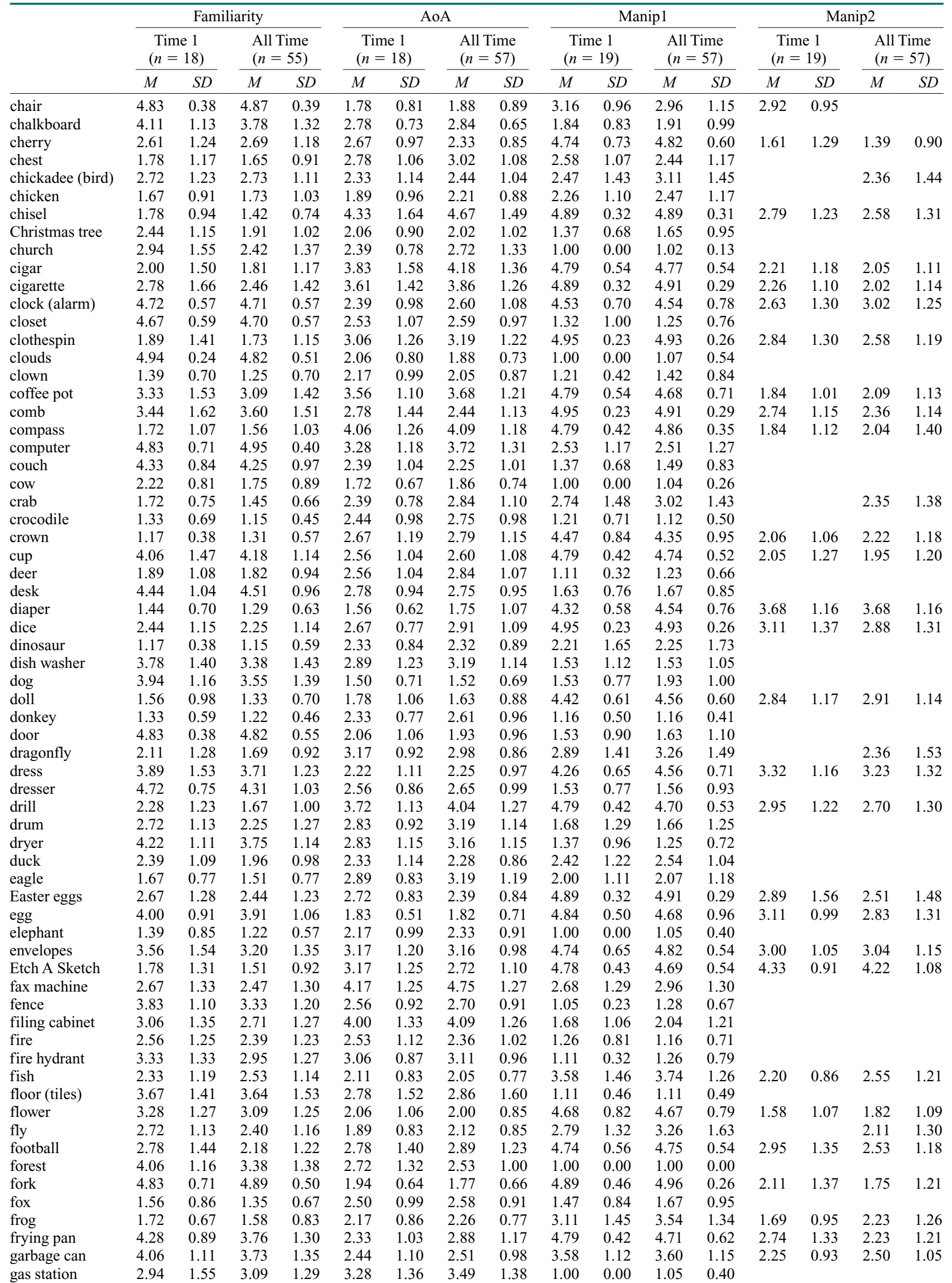


APPENDIX B (Continued)

\begin{tabular}{|c|c|c|c|c|c|c|c|c|c|c|c|c|c|c|c|c|}
\hline & \multicolumn{4}{|c|}{ Familiarity } & \multicolumn{4}{|c|}{ AoA } & \multicolumn{4}{|c|}{ Manip1 } & \multicolumn{4}{|c|}{ Manip2 } \\
\hline & \multicolumn{2}{|c|}{$\begin{array}{c}\text { Time } 1 \\
(n=18)\end{array}$} & \multicolumn{2}{|c|}{$\begin{array}{l}\text { All Time } \\
(n=55)\end{array}$} & $\begin{array}{l}\text { Tir } \\
(n=\end{array}$ & $\begin{array}{l}1 \\
18) \\
\end{array}$ & & & & $\begin{array}{l}1 \\
19) \\
\end{array}$ & & ne & & & & \\
\hline & $M$ & $S D$ & $M$ & $S D$ & $M$ & $S D$ & $M$ & $S D$ & $M$ & $S D$ & $M$ & $S D$ & $M$ & $S D$ & $M$ & $S D$ \\
\hline gazebo & 2.56 & 1.04 & 1.87 & 1.00 & 4.50 & 1.50 & 4.65 & 1.30 & 1.11 & 0.46 & 1.05 & 0.29 & & & & \\
\hline giraffe & 1.44 & 0.78 & 1.24 & 0.58 & 2.72 & 1.23 & 2.58 & 1.05 & 1.05 & 0.23 & 1.11 & 0.56 & & & & \\
\hline glasses & 4.11 & 1.45 & 3.89 & 1.56 & 2.11 & 0.76 & 2.33 & 0.89 & 4.89 & 0.32 & 4.89 & 0.36 & 2.53 & 1.17 & 2.54 & 1.30 \\
\hline glove & 3.39 & 1.38 & 3.33 & 1.36 & 2.22 & 0.81 & 2.40 & 0.96 & 4.79 & 0.42 & 4.70 & 0.73 & 2.79 & 1.44 & 2.76 & 1.26 \\
\hline goat & 1.39 & 0.85 & 1.24 & 0.61 & 2.39 & 1.09 & 2.82 & 1.17 & 1.21 & 0.42 & 1.33 & 0.72 & & & & \\
\hline gorilla & 1.39 & 0.85 & 1.33 & 0.79 & 3.00 & 0.94 & 2.80 & 1.00 & 1.11 & 0.32 & 1.07 & 0.26 & & & & \\
\hline grapes & 3.67 & 1.14 & 3.58 & 1.10 & 2.00 & 0.59 & 2.00 & 0.60 & 4.89 & 0.32 & 4.93 & 0.26 & 1.63 & 1.26 & 1.60 & 1.13 \\
\hline grass & 4.00 & 0.91 & 4.09 & 1.02 & 1.89 & 0.83 & 1.82 & 0.85 & 2.56 & 1.69 & 2.80 & 1.53 & & & & \\
\hline guitar & 3.56 & 1.50 & 3.06 & 1.46 & 2.89 & 0.90 & 3.07 & 1.00 & 4.00 & 0.94 & 3.98 & 1.09 & 4.41 & 0.87 & 4.27 & 1.13 \\
\hline gun & 1.67 & 0.97 & 1.62 & 1.06 & 3.22 & 1.26 & 3.56 & 1.20 & 4.95 & 0.23 & 4.82 & 0.58 & 2.58 & 1.35 & 2.60 & 1.30 \\
\hline hair dryer & 3.61 & 1.61 & 3.74 & 1.51 & 3.17 & 1.10 & 3.46 & 1.25 & 4.79 & 0.42 & 4.79 & 0.45 & 2.84 & 1.21 & 2.44 & 1.18 \\
\hline Halifax Citadel* & 2.72 & 1.71 & 2.40 & 1.38 & 4.82 & 1.74 & 4.93 & 1.63 & 1.00 & 0.00 & 1.16 & 0.75 & & & & \\
\hline harp & 1.56 & 0.98 & 1.24 & 0.67 & 3.67 & 1.50 & 4.21 & 1.28 & 2.74 & 1.41 & 2.67 & 1.35 & & & & \\
\hline hat & 3.61 & 1.33 & 3.09 & 1.51 & 2.28 & 1.27 & 1.95 & 1.01 & 4.53 & 1.07 & 4.79 & 0.67 & 1.78 & 1.06 & 2.02 & 1.20 \\
\hline helicopter & 1.89 & 0.83 & 1.73 & 0.89 & 3.11 & 1.02 & 3.21 & 1.11 & 1.32 & 1.00 & 1.19 & 0.72 & & & & \\
\hline high chair & 1.83 & 1.15 & 1.40 & 0.81 & 1.78 & 0.73 & 1.91 & 1.14 & 2.00 & 1.00 & 2.23 & 1.08 & & & & \\
\hline hole punch & 3.33 & 1.46 & 3.38 & 1.34 & 4.33 & 0.91 & 4.14 & 1.01 & 4.79 & 0.42 & 4.70 & 0.53 & 3.22 & 1.22 & 3.21 & 1.16 \\
\hline horse & 1.83 & 0.71 & 1.62 & 0.83 & 2.44 & 1.62 & 2.12 & 1.12 & 1.11 & 0.32 & 1.09 & 0.34 & & & & \\
\hline house & 4.56 & 1.04 & 4.58 & 0.85 & 2.00 & 0.87 & 1.86 & 0.86 & 1.00 & 0.00 & 1.19 & 0.83 & & & & \\
\hline ice scraper & 3.28 & 1.74 & 3.13 & 1.55 & 3.28 & 1.45 & 3.74 & 1.55 & 4.74 & 0.45 & 4.82 & 0.38 & 3.37 & 1.12 & 2.86 & 1.22 \\
\hline iron & 3.00 & 1.24 & 2.71 & 1.23 & 3.39 & 1.42 & 3.61 & 1.31 & 4.89 & 0.32 & 4.60 & 0.76 & 2.74 & 1.37 & 2.35 & 1.28 \\
\hline ironing board & 2.83 & 1.42 & 2.55 & 1.26 & 3.17 & 1.25 & 3.51 & 1.18 & 3.47 & 0.96 & 3.23 & 1.09 & 3.40 & 1.24 & 3.21 & 1.28 \\
\hline jacket & 4.56 & 0.86 & 4.67 & 0.61 & 2.44 & 0.78 & 2.07 & 0.84 & 4.37 & 0.68 & 4.39 & 0.87 & 3.16 & 1.26 & 3.31 & 1.22 \\
\hline jack-o-lantern & 2.28 & 1.32 & 1.71 & 1.01 & 2.61 & 0.70 & 2.39 & 0.73 & 3.74 & 0.99 & 3.84 & 1.05 & 3.13 & 1.46 & 2.88 & 1.39 \\
\hline jelly beans & 2.78 & 1.35 & 2.62 & 1.25 & 2.39 & 0.85 & 2.32 & 0.83 & 4.84 & 0.50 & 4.82 & 0.63 & 1.32 & 0.95 & 1.31 & 0.94 \\
\hline kangaroo & 1.44 & 0.92 & 1.22 & 0.60 & 2.78 & 1.00 & 2.95 & 1.09 & 1.16 & 0.37 & 1.14 & 0.35 & & & & \\
\hline kettle & 4.33 & 1.03 & 3.76 & 1.35 & 2.89 & 1.28 & 3.18 & 1.09 & 4.53 & 0.51 & 4.53 & 0.63 & 2.42 & 1.17 & 2.46 & 1.31 \\
\hline key & 4.67 & 0.97 & 4.67 & 0.94 & 2.78 & 1.22 & 2.70 & 1.00 & 4.95 & 0.23 & 4.91 & 0.54 & 3.47 & 1.50 & 3.09 & 1.37 \\
\hline ladder & 2.22 & 0.94 & 1.76 & 0.86 & 2.67 & 0.77 & 2.81 & 0.93 & 2.63 & 1.30 & 2.63 & 1.20 & & & & \\
\hline lamp & 4.56 & 0.98 & 4.38 & 1.10 & 2.22 & 0.81 & 2.23 & 0.85 & 3.74 & 1.10 & 3.63 & 1.15 & 3.19 & 1.22 & 2.93 & 1.25 \\
\hline lawn mower & 2.11 & 1.18 & 1.73 & 0.91 & 3.00 & 0.91 & 3.12 & 1.13 & 2.26 & 1.33 & 2.23 & 1.18 & & & & \\
\hline leaf & 3.78 & 1.26 & 3.64 & 1.16 & 2.44 & 0.98 & 2.26 & 0.95 & 4.53 & 1.07 & 4.72 & 0.80 & 2.11 & 1.18 & 1.89 & 1.13 \\
\hline Lego & 1.61 & 0.85 & 1.51 & 0.82 & 2.00 & 0.79 & 1.82 & 0.83 & 4.79 & 0.42 & 4.84 & 0.41 & 3.74 & 1.19 & 3.12 & 1.32 \\
\hline lemon & 3.61 & 1.04 & 3.15 & 1.15 & 2.76 & 1.03 & 2.66 & 0.86 & 4.89 & 0.32 & 4.84 & 0.42 & 2.37 & 1.26 & 2.14 & 1.17 \\
\hline leopard & 1.44 & 0.78 & 1.25 & 0.62 & 2.94 & 1.35 & 3.11 & 1.22 & 1.05 & 0.23 & 1.21 & 0.65 & & & & \\
\hline lettuce & 4.28 & 0.96 & 4.04 & 1.05 & 2.78 & 0.88 & 2.75 & 0.97 & 4.68 & 0.58 & 4.70 & 0.57 & 3.16 & 1.21 & 2.74 & 1.14 \\
\hline light bulb & 4.44 & 0.98 & 4.29 & 1.01 & 2.72 & 0.96 & 2.84 & 1.00 & 4.68 & 0.67 & 4.72 & 0.56 & 3.37 & 1.12 & 3.11 & 1.29 \\
\hline lion & 1.56 & 1.04 & 1.29 & 0.74 & 1.89 & 0.76 & 2.21 & 0.90 & 1.11 & 0.46 & 1.05 & 0.29 & & & & \\
\hline lobster & 2.61 & 1.20 & 1.93 & 1.03 & 2.89 & 1.41 & 3.21 & 1.40 & 3.56 & 1.15 & 3.55 & 1.19 & 2.47 & 1.37 & 2.96 & 1.35 \\
\hline lock & 2.67 & 1.37 & 2.65 & 1.28 & 3.67 & 1.24 & 3.93 & 1.32 & 4.84 & 0.37 & 4.86 & 0.35 & 3.89 & 1.33 & 3.89 & 1.11 \\
\hline LSC & 4.67 & 0.69 & 4.44 & 0.90 & 3.82 & 1.88 & 4.66 & 2.13 & 1.00 & 0.00 & 1.07 & 0.53 & & & & \\
\hline manhole cover & 3.50 & 1.34 & 3.13 & 1.40 & 4.06 & 1.39 & 4.00 & 1.20 & 1.26 & 0.45 & 1.30 & 0.53 & & & & \\
\hline maracas & 1.50 & 0.86 & 1.22 & 0.57 & 3.67 & 0.97 & 3.75 & 1.19 & 4.68 & 0.48 & 4.77 & 0.50 & 2.89 & 1.29 & 2.42 & 1.24 \\
\hline marker & 3.78 & 0.94 & 3.96 & 1.04 & 2.94 & 1.16 & 2.33 & 1.02 & 4.95 & 0.23 & 4.91 & 0.34 & 3.58 & 1.17 & 3.04 & 1.31 \\
\hline milk & 4.78 & 0.65 & 4.55 & 0.81 & 2.17 & 1.04 & 1.79 & 0.90 & 4.67 & 0.59 & 4.61 & 0.76 & 2.39 & 1.33 & 2.00 & 1.22 \\
\hline mitten & 3.72 & 0.96 & 3.64 & 1.18 & 1.89 & 0.83 & 2.04 & 1.00 & 4.95 & 0.23 & 4.88 & 0.47 & 2.84 & 1.26 & 2.52 & 1.19 \\
\hline mixer & 2.83 & 1.25 & 2.20 & 1.19 & 3.39 & 0.70 & 3.68 & 1.17 & 3.11 & 1.10 & 3.16 & 1.11 & 3.31 & 1.18 & 3.38 & 1.19 \\
\hline monkey & 1.50 & 0.71 & 1.42 & 0.76 & 2.17 & 1.10 & 2.35 & 0.99 & 1.84 & 1.07 & 2.00 & 1.21 & & & & \\
\hline monument & 2.72 & 1.23 & 2.33 & 1.36 & 4.39 & 1.61 & 4.86 & 1.52 & 1.00 & 0.00 & 1.02 & 0.13 & & & & \\
\hline moon & 4.56 & 0.86 & 4.49 & 0.74 & 1.89 & 1.13 & 2.11 & 0.99 & 1.00 & 0.00 & 1.00 & 0.00 & & & & \\
\hline motorcycle & 2.50 & 0.99 & 2.25 & 1.09 & 2.67 & 0.91 & 3.35 & 1.25 & 1.37 & 0.96 & 1.26 & 0.74 & & & & \\
\hline mountain & 2.44 & 1.34 & 2.09 & 1.19 & 2.94 & 1.06 & 3.19 & 1.20 & 1.00 & 0.00 & 1.11 & 0.59 & & & & \\
\hline mouse & 1.72 & 0.89 & 1.69 & 0.84 & 2.22 & 0.73 & 2.19 & 0.81 & 3.42 & 1.26 & 3.70 & 1.27 & 1.71 & 0.99 & 2.18 & 1.32 \\
\hline movie theatre & 4.22 & 1.31 & 4.05 & 1.37 & 4.24 & 1.68 & 4.64 & 1.59 & 1.00 & 0.00 & 1.02 & 0.13 & & & & \\
\hline Mr. Potato Head & 1.78 & 1.26 & 1.35 & 0.91 & 2.61 & 0.85 & 2.18 & 1.00 & 4.68 & 0.48 & 4.72 & 0.53 & 4.53 & 0.61 & 3.93 & 1.15 \\
\hline mushroom & 3.56 & 1.54 & 3.22 & 1.30 & 2.72 & 1.02 & 2.74 & 1.06 & 4.84 & 0.50 & 4.75 & 0.71 & 1.89 & 1.13 & 1.75 & 0.97 \\
\hline nails & 2.78 & 1.31 & 2.07 & 1.15 & 2.94 & 1.11 & 3.07 & 1.04 & 4.89 & 0.32 & 4.88 & 0.38 & 3.53 & 1.07 & 3.37 & 1.20 \\
\hline necklace & 3.22 & 1.52 & 3.82 & 1.33 & 2.44 & 1.10 & 2.53 & 0.98 & 4.79 & 0.54 & 4.68 & 0.76 & 2.74 & 1.19 & 2.78 & 1.23 \\
\hline onion & 4.28 & 0.96 & 3.67 & 1.02 & 2.11 & 0.68 & 2.65 & 0.86 & 4.89 & 0.32 & 4.88 & 0.38 & 2.68 & 1.16 & 2.32 & 1.17 \\
\hline orange & 4.39 & 0.78 & 4.18 & 1.04 & 1.78 & 0.73 & 1.86 & 0.74 & 4.88 & 0.49 & 4.95 & 0.30 & 3.00 & 1.33 & 2.30 & 1.36 \\
\hline
\end{tabular}


APPENDIX B (Continued)

\begin{tabular}{|c|c|c|c|c|c|c|c|c|c|c|c|c|c|c|c|c|}
\hline & \multicolumn{4}{|c|}{ Familiarity } & \multicolumn{4}{|c|}{ AoA } & \multicolumn{4}{|c|}{ Manip1 } & \multicolumn{4}{|c|}{ Manip2 } \\
\hline & \multicolumn{2}{|c|}{$\begin{array}{c}\text { Time } 1 \\
(n=18)\end{array}$} & \multicolumn{2}{|c|}{$\begin{array}{l}\text { All Time } \\
(n=55)\end{array}$} & $\begin{array}{l}\mathrm{Ti} \\
(n\end{array}$ & $\begin{array}{l}\text { e } 1 \\
18) \\
\end{array}$ & & & & & & & & & & ne \\
\hline & $M$ & $S D$ & $M$ & $S D$ & $M$ & $S D$ & $M$ & $S D$ & $M$ & $S D$ & $M$ & $S D$ & $M$ & $S D$ & $M$ & $S D$ \\
\hline owl & 1.50 & 0.62 & 1.49 & 0.69 & 2.53 & 0.87 & 2.55 & 0.87 & 2.11 & 1.10 & 2.28 & 1.21 & & & & \\
\hline pacifier & 1.39 & 0.85 & 1.15 & 0.52 & 2.11 & 1.45 & 1.82 & 1.31 & 4.95 & 0.23 & 4.88 & 0.47 & 2.95 & 1.65 & 2.46 & 1.40 \\
\hline paintbrush & 2.17 & 1.25 & 2.00 & 1.15 & 2.50 & 0.99 & 2.70 & 1.03 & 4.89 & 0.46 & 4.84 & 0.45 & 2.79 & 1.36 & 2.53 & 1.28 \\
\hline pants & 4.89 & 0.47 & 4.89 & 0.37 & 2.39 & 0.98 & 2.26 & 0.94 & 4.53 & 0.84 & 4.54 & 0.68 & 2.84 & 1.30 & 3.02 & 1.27 \\
\hline parking meter & 3.67 & 1.46 & 2.95 & 1.39 & 4.33 & 1.28 & 4.43 & 1.28 & 1.47 & 1.17 & 1.37 & 0.82 & & & & \\
\hline parrot & 1.50 & 1.04 & 1.29 & 0.69 & 2.72 & 1.23 & 2.75 & 1.01 & 2.53 & 1.17 & 2.65 & 1.16 & & & & \\
\hline peach & 4.00 & 1.08 & 3.45 & 1.26 & 2.24 & 0.83 & 2.20 & 0.84 & 5.00 & 0.00 & 4.93 & 0.26 & 1.21 & 0.92 & 1.21 & 0.73 \\
\hline peacock & 1.61 & 0.92 & 1.38 & 0.73 & 3.61 & 1.65 & 3.44 & 1.32 & 1.89 & 0.74 & 1.95 & 1.00 & & & & \\
\hline pear & 2.94 & 1.39 & 3.15 & 1.30 & 2.39 & 0.98 & 2.21 & 0.82 & 4.89 & 0.46 & 4.91 & 0.34 & 1.21 & 0.92 & 1.19 & 0.67 \\
\hline pen & 4.89 & 0.47 & 4.96 & 0.27 & 2.56 & 0.62 & 2.56 & 0.91 & 5.00 & 0.00 & 4.96 & 0.19 & 3.21 & 1.40 & 3.21 & 1.39 \\
\hline penguin & 1.39 & 0.85 & 1.27 & 0.62 & 2.56 & 0.78 & 2.81 & 1.16 & 1.42 & 0.61 & 1.54 & 0.80 & & & & \\
\hline pepper (bell) & 3.94 & 1.35 & 3.62 & 1.35 & 2.89 & 0.76 & 3.00 & 1.09 & 5.00 & 0.00 & 4.86 & 0.58 & 2.21 & 1.27 & 2.12 & 1.05 \\
\hline pigeon & 3.83 & 1.34 & 3.35 & 1.42 & 2.39 & 1.04 & 2.70 & 1.05 & 2.37 & 1.16 & 2.70 & 1.28 & & & & \\
\hline pineapple & 3.00 & 1.28 & 2.80 & 1.23 & 2.61 & 1.14 & 2.88 & 1.12 & 4.42 & 0.61 & 4.53 & 0.57 & 2.89 & 1.33 & 2.95 & 1.34 \\
\hline pipe & 1.78 & 1.31 & 1.62 & 1.11 & 3.44 & 1.20 & 4.16 & 1.33 & 4.95 & 0.23 & 4.82 & 0.60 & 2.37 & 1.12 & 2.36 & 1.26 \\
\hline pitcher & 2.44 & 1.38 & 1.93 & 1.16 & 3.44 & 1.29 & 3.39 & 1.18 & 4.37 & 0.83 & 4.35 & 0.92 & 1.94 & 1.06 & 1.96 & 0.96 \\
\hline plate & 4.67 & 1.03 & 4.82 & 0.72 & 1.67 & 0.49 & 1.79 & 0.70 & 4.79 & 0.42 & 4.82 & 0.38 & 1.95 & 1.13 & 2.07 & 1.22 \\
\hline pliers & 2.17 & 1.10 & 1.73 & 0.95 & 3.78 & 1.31 & 4.07 & 1.22 & 4.89 & 0.32 & 4.91 & 0.29 & 2.94 & 1.26 & 2.89 & 1.21 \\
\hline plug & 4.72 & 0.83 & 4.64 & 0.73 & 3.00 & 1.14 & 2.89 & 1.18 & 4.63 & 0.60 & 4.72 & 0.65 & 2.05 & 1.27 & 1.95 & 1.21 \\
\hline police car & 3.28 & 1.41 & 3.04 & 1.19 & 2.89 & 1.32 & 3.07 & 1.10 & 1.21 & 0.71 & 1.12 & 0.57 & & & & \\
\hline pool table & 3.33 & 1.28 & 2.51 & 1.39 & 3.50 & 1.15 & 4.21 & 1.37 & 1.47 & 0.90 & 1.37 & 0.88 & & & & \\
\hline popsicle/lollipop & 2.78 & 1.06 & 2.36 & 1.08 & 2.17 & 0.51 & 2.11 & 0.79 & 4.63 & 0.83 & 4.84 & 0.53 & 1.83 & 1.25 & 1.63 & 1.05 \\
\hline pot & 4.11 & 1.32 & 3.65 & 1.35 & 2.78 & 1.26 & 2.84 & 1.08 & 4.58 & 0.61 & 4.49 & 0.68 & 2.32 & 1.16 & 2.11 & 1.17 \\
\hline potato & 3.94 & 1.30 & 3.78 & 1.13 & 2.56 & 0.86 & 2.53 & 0.87 & 4.89 & 0.32 & 4.89 & 0.31 & 2.47 & 1.17 & 2.40 & 1.28 \\
\hline present & 2.39 & 1.24 & 2.36 & 1.09 & 2.33 & 0.77 & 1.89 & 0.77 & 4.21 & 1.08 & 4.32 & 0.91 & 4.00 & 1.22 & 3.48 & 1.31 \\
\hline prison & 1.11 & 0.32 & 1.27 & 0.73 & 3.56 & 1.04 & 3.88 & 1.30 & 1.05 & 0.23 & 1.02 & 0.13 & & & & \\
\hline protractor & 2.50 & 1.34 & 2.24 & 1.20 & 4.56 & 1.34 & 4.86 & 1.27 & 4.89 & 0.32 & 4.86 & 0.40 & 3.58 & 0.96 & 3.32 & 1.07 \\
\hline purse & 3.89 & 1.53 & 3.98 & 1.39 & 2.89 & 1.02 & 2.72 & 0.86 & 4.42 & 1.02 & 4.49 & 0.87 & 2.72 & 1.07 & 2.73 & 1.29 \\
\hline raspberry & 2.50 & 1.29 & 2.67 & 1.17 & 2.83 & 1.10 & 2.67 & 1.04 & 4.84 & 0.50 & 4.86 & 0.52 & 1.21 & 0.92 & 1.23 & 0.71 \\
\hline refrigerator & 4.72 & 0.46 & 4.69 & 0.64 & 2.28 & 0.96 & 2.39 & 1.05 & 1.32 & 0.82 & 1.35 & 0.88 & & & & \\
\hline remote control & 4.28 & 1.32 & 4.20 & 1.18 & 2.72 & 0.83 & 2.95 & 1.03 & 4.95 & 0.23 & 4.93 & 0.26 & 3.79 & 1.62 & 3.65 & 1.66 \\
\hline ring & 3.22 & 1.59 & 3.38 & 1.48 & 2.71 & 1.21 & 2.71 & 1.09 & 4.89 & 0.46 & 4.88 & 0.50 & 2.53 & 1.12 & 2.45 & 1.25 \\
\hline road & 4.56 & 0.98 & 4.71 & 0.69 & 2.28 & 0.96 & 2.23 & 0.95 & 1.11 & 0.46 & 1.14 & 0.64 & & & & \\
\hline rocking horse & 1.72 & 1.27 & 1.35 & 0.82 & 2.50 & 1.38 & 2.12 & 1.23 & 2.63 & 0.83 & 2.61 & 0.98 & & & & \\
\hline Rolodex & 2.94 & 1.39 & 2.35 & 1.33 & 4.39 & 1.54 & 4.63 & 1.38 & 4.26 & 0.87 & 4.23 & 0.93 & 3.39 & 1.20 & 3.56 & 1.22 \\
\hline roof & 4.39 & 0.92 & 4.04 & 1.15 & 2.33 & 0.84 & 2.70 & 0.91 & 1.11 & 0.46 & 1.07 & 0.32 & & & & \\
\hline rooster & 1.56 & 0.78 & 1.53 & 0.84 & 2.39 & 0.78 & 2.40 & 0.86 & 2.47 & 1.31 & 2.42 & 1.25 & & & & \\
\hline roulette wheel & 1.44 & 1.04 & 1.36 & 0.82 & 5.17 & 1.69 & 5.53 & 1.39 & 1.68 & 1.00 & 1.77 & 1.13 & & & & \\
\hline Rowe Building* & 3.78 & 1.52 & 3.71 & 1.31 & 4.17 & 1.98 & 4.72 & 2.10 & 1.00 & 0.00 & 1.00 & 0.00 & & & & \\
\hline ruler & 3.61 & 1.20 & 3.31 & 1.18 & 3.00 & 0.84 & 3.09 & 0.85 & 4.84 & 0.37 & 4.89 & 0.31 & 2.84 & 1.12 & 2.79 & 1.11 \\
\hline sailboat & 2.28 & 1.13 & 2.11 & 1.17 & 2.39 & 0.70 & 2.53 & 0.95 & 1.26 & 0.81 & 1.21 & 0.75 & & & & \\
\hline salt shaker & 4.11 & 1.28 & 4.11 & 1.15 & 2.33 & 0.59 & 2.60 & 0.96 & 4.89 & 0.32 & 4.91 & 0.29 & 2.63 & 1.26 & 2.37 & 1.14 \\
\hline sandbox & 1.39 & 0.50 & 1.40 & 0.66 & 2.33 & 1.19 & 1.95 & 0.95 & 1.53 & 0.90 & 1.41 & 0.83 & & & & \\
\hline sandwich & 4.11 & 0.96 & 4.31 & 0.84 & 2.22 & 0.73 & 2.30 & 0.91 & 4.79 & 0.42 & 4.70 & 0.53 & 2.11 & 1.33 & 1.74 & 1.06 \\
\hline Santa Claus & 2.28 & 1.32 & 1.82 & 1.12 & 2.00 & 0.97 & 1.61 & 0.82 & 1.21 & 0.42 & 1.37 & 0.88 & & & & \\
\hline saw & 2.44 & 0.98 & 1.76 & 0.88 & 3.33 & 1.08 & 3.47 & 1.02 & 4.42 & 0.96 & 4.33 & 1.07 & 3.78 & 1.17 & 2.98 & 1.35 \\
\hline scarf & 4.11 & 0.90 & 4.04 & 1.13 & 2.78 & 1.11 & 2.86 & 1.03 & 4.89 & 0.32 & 4.81 & 0.48 & 2.79 & 1.03 & 2.67 & 1.19 \\
\hline scissors & 3.56 & 1.15 & 3.64 & 1.22 & 2.28 & 0.67 & 2.33 & 0.72 & 5.00 & 0.00 & 4.96 & 0.19 & 3.47 & 1.26 & 3.19 & 1.17 \\
\hline screw & 2.56 & 1.29 & 2.04 & 1.12 & 3.33 & 0.84 & 3.21 & 1.06 & 4.89 & 0.32 & 4.86 & 0.44 & 2.89 & 1.24 & 3.13 & 1.29 \\
\hline screwdriver & 2.56 & 1.29 & 2.07 & 1.14 & 3.61 & 1.09 & 3.65 & 1.23 & 5.00 & 0.00 & 4.96 & 0.19 & 3.63 & 1.12 & 3.25 & 1.20 \\
\hline seagull & 3.11 & 1.32 & 2.71 & 1.24 & 2.78 & 0.94 & 2.65 & 0.97 & 2.16 & 1.12 & 2.32 & 1.20 & & & & \\
\hline seahorse & 1.50 & 1.15 & 1.24 & 0.79 & 3.61 & 1.20 & 3.49 & 1.24 & 2.58 & 1.39 & 2.93 & 1.51 & & & & \\
\hline seal & 1.56 & 0.98 & 1.31 & 0.72 & 2.94 & 1.26 & 3.04 & 1.12 & 1.37 & 0.50 & 1.35 & 0.64 & & & & \\
\hline sewing machine & 1.82 & 1.13 & 1.74 & 0.96 & 3.72 & 1.23 & 3.74 & 1.17 & 3.05 & 1.08 & 3.12 & 1.02 & 4.00 & 1.11 & 3.96 & 1.28 \\
\hline sheep & 1.56 & 1.04 & 1.36 & 0.85 & 2.22 & 1.06 & 2.35 & 0.95 & 1.21 & 0.42 & 1.39 & 0.75 & & & & \\
\hline shell & 2.22 & 1.22 & 1.75 & 1.11 & 2.61 & 1.09 & 2.60 & 1.15 & 4.42 & 1.07 & 4.61 & 0.92 & 2.00 & 1.46 & 2.02 & 1.28 \\
\hline shovel & 2.44 & 1.25 & 2.00 & 1.02 & 2.50 & 0.62 & 2.88 & 1.01 & 4.32 & 0.89 & 4.29 & 0.99 & 3.56 & 0.98 & 3.15 & 1.13 \\
\hline shower & 4.94 & 0.24 & 4.80 & 0.73 & 3.00 & 1.24 & 2.75 & 1.31 & 1.50 & 1.04 & 1.25 & 0.74 & & & & \\
\hline $\operatorname{sink}$ & 4.89 & 0.32 & 4.95 & 0.23 & 2.11 & 1.02 & 2.18 & 0.85 & 1.32 & 0.82 & 1.44 & 1.02 & & & & \\
\hline sippy cup & 1.39 & 0.78 & 1.22 & 0.57 & 1.44 & 0.51 & 1.47 & 0.78 & 4.89 & 0.32 & 4.88 & 0.33 & 1.68 & 1.00 & 1.63 & 0.96 \\
\hline
\end{tabular}


APPENDIX B (Continued)

\begin{tabular}{|c|c|c|c|c|c|c|c|c|c|c|c|c|c|c|c|c|}
\hline & \multicolumn{4}{|c|}{ Familiarity } & \multicolumn{4}{|c|}{ AoA } & \multicolumn{4}{|c|}{ Manip1 } & \multicolumn{4}{|c|}{ Manip2 } \\
\hline & \multicolumn{2}{|c|}{$\begin{array}{c}\text { Time } 1 \\
(n=18)\end{array}$} & \multicolumn{2}{|c|}{$\begin{array}{l}\text { All Time } \\
(n=55)\end{array}$} & \multicolumn{2}{|c|}{$\begin{array}{c}\text { Time 1 } \\
(n=18)\end{array}$} & \multicolumn{2}{|c|}{$\begin{array}{l}\text { All Time } \\
(n=57)\end{array}$} & \multicolumn{2}{|c|}{$\begin{array}{c}\text { Time 1 } \\
(n=19)\end{array}$} & & ime & & & & $\begin{array}{l}\text { ime } \\
57)\end{array}$ \\
\hline & $M$ & $S D$ & $M$ & $S D$ & $M$ & $S D$ & $M$ & $S D$ & $M$ & $S D$ & $M$ & $S D$ & $M$ & $S D$ & $M$ & $S D$ \\
\hline slide & 1.94 & 1.00 & 1.73 & 0.89 & 1.88 & 0.72 & 1.91 & 0.93 & 1.26 & 0.73 & 1.21 & 0.53 & & & & \\
\hline slot machine & 1.61 & 1.04 & 1.45 & 0.92 & 5.22 & 1.48 & 5.28 & 1.45 & 1.50 & 1.10 & 1.61 & 1.19 & & & & \\
\hline snail & 1.67 & 0.84 & 1.42 & 0.69 & 2.56 & 1.15 & 2.67 & 0.91 & 3.63 & 1.34 & 3.93 & 1.43 & 1.80 & 0.94 & 2.00 & 1.26 \\
\hline snake & 1.72 & 1.02 & 1.45 & 0.88 & 2.28 & 0.83 & 2.44 & 0.98 & 2.42 & 1.35 & 2.53 & 1.45 & & & & \\
\hline snowflake & 2.94 & 1.39 & 3.29 & 1.29 & 2.61 & 0.85 & 2.47 & 1.10 & 3.53 & 1.58 & 3.51 & 1.62 & 1.94 & 1.29 & 2.07 & 1.40 \\
\hline sock & 4.67 & 0.84 & 4.78 & 0.66 & 2.00 & 1.08 & 1.77 & 0.91 & 4.79 & 0.54 & 4.84 & 0.45 & 3.00 & 1.37 & 3.02 & 1.29 \\
\hline spider & 1.56 & 0.70 & 1.44 & 0.71 & 3.00 & 1.14 & 2.93 & 1.10 & 3.26 & 1.28 & 3.56 & 1.46 & 1.93 & 0.88 & 2.39 & 1.42 \\
\hline spider web & 2.65 & 1.11 & 2.04 & 1.03 & 2.61 & 0.78 & 2.61 & 0.88 & 1.68 & 1.11 & 2.58 & 1.64 & & & & \\
\hline stairs & 4.44 & 1.20 & 4.76 & 0.74 & 1.78 & 0.65 & 1.84 & 0.84 & 1.16 & 0.69 & 1.07 & 0.42 & & & & \\
\hline staple gun & 2.17 & 1.29 & 2.07 & 1.25 & 3.94 & 1.16 & 4.12 & 1.21 & 4.68 & 0.48 & 4.67 & 0.72 & 3.05 & 1.08 & 2.75 & 1.21 \\
\hline staple remover & 4.00 & 0.97 & 3.91 & 0.93 & 3.44 & 0.98 & 3.47 & 1.00 & 4.74 & 0.56 & 4.81 & 0.44 & 3.58 & 1.17 & 3.14 & 1.25 \\
\hline stapler & 2.22 & 1.17 & 2.38 & 1.16 & 4.39 & 1.65 & 4.61 & 1.39 & 4.95 & 0.23 & 4.82 & 0.61 & 3.16 & 1.38 & 2.84 & 1.30 \\
\hline statue & 1.61 & 0.92 & 1.50 & 0.88 & 4.24 & 1.56 & 4.55 & 1.54 & 1.21 & 0.71 & 1.18 & 0.68 & & & & \\
\hline stocking & 2.06 & 1.00 & 1.73 & 0.97 & 2.39 & 1.04 & 2.09 & 0.85 & 4.53 & 0.77 & 4.49 & 0.83 & 2.63 & 1.54 & 2.68 & 1.38 \\
\hline stool & 3.72 & 1.32 & 3.37 & 1.20 & 2.72 & 1.07 & 2.53 & 1.02 & 3.39 & 1.09 & 3.46 & 1.01 & 3.13 & 1.36 & 2.75 & 1.31 \\
\hline stove & 4.44 & 1.10 & 4.04 & 1.33 & 2.00 & 0.84 & 2.26 & 0.88 & 1.42 & 0.90 & 1.30 & 0.80 & & & & \\
\hline strawberry & 3.56 & 1.50 & 3.45 & 1.32 & 2.00 & 0.69 & 2.02 & 0.67 & 5.00 & 0.00 & 4.91 & 0.54 & 1.58 & 1.26 & 1.39 & 0.89 \\
\hline stroller & 1.72 & 0.96 & 1.56 & 0.90 & 2.50 & 1.20 & 2.26 & 1.22 & 2.47 & 1.07 & 2.42 & 1.10 & & & & \\
\hline SUB* & 4.33 & 1.19 & 4.36 & 1.02 & 4.00 & 1.88 & 4.77 & 2.12 & 1.00 & 0.00 & 1.00 & 0.00 & & & & \\
\hline suitcase & 2.78 & 1.31 & 2.65 & 1.25 & 3.11 & 0.90 & 3.30 & 1.02 & 4.21 & 0.79 & 4.30 & 0.82 & 1.94 & 1.11 & 2.29 & 1.23 \\
\hline sweatshirt & 4.50 & 1.15 & 4.71 & 0.79 & 2.28 & 1.18 & 2.19 & 0.90 & 4.47 & 0.70 & 4.56 & 0.73 & 2.84 & 1.26 & 3.00 & 1.13 \\
\hline swing set & 1.89 & 0.96 & 1.87 & 0.79 & 2.00 & 0.59 & 1.93 & 0.59 & 1.47 & 1.02 & 1.37 & 0.77 & & & & \\
\hline table & 4.67 & 0.59 & 4.64 & 0.70 & 2.00 & 0.97 & 2.12 & 0.96 & 2.21 & 0.98 & 2.18 & 0.98 & & & & \\
\hline tambourine & 2.00 & 1.24 & 1.55 & 0.92 & 3.22 & 1.22 & 3.32 & 1.15 & 4.79 & 0.42 & 4.82 & 0.43 & 2.95 & 1.39 & 2.60 & 1.28 \\
\hline tape measure & 2.50 & 1.25 & 2.07 & 1.03 & 3.39 & 1.04 & 3.60 & 1.07 & 4.89 & 0.32 & 4.79 & 0.62 & 3.61 & 1.04 & 3.56 & 1.25 \\
\hline telephone & 4.83 & 0.38 & 4.87 & 0.34 & 2.11 & 1.18 & 2.16 & 1.10 & 4.42 & 0.61 & 4.61 & 0.56 & 3.26 & 1.41 & 3.48 & 1.45 \\
\hline television & 4.06 & 1.55 & 4.45 & 1.15 & 2.22 & 1.06 & 2.19 & 1.09 & 1.89 & 0.94 & 2.02 & 1.09 & & & & \\
\hline thread & 2.28 & 1.36 & 1.91 & 1.13 & 3.06 & 0.94 & 3.21 & 1.01 & 4.95 & 0.23 & 4.88 & 0.33 & 3.84 & 1.07 & 3.68 & 1.19 \\
\hline tie & 2.72 & 1.41 & 2.15 & 1.19 & 3.06 & 0.94 & 3.00 & 1.02 & 4.53 & 0.70 & 4.70 & 0.53 & 3.72 & 1.18 & 3.79 & 1.16 \\
\hline tiger & 1.28 & 0.67 & 1.22 & 0.50 & 2.06 & 0.80 & 2.28 & 0.82 & 1.11 & 0.32 & 1.16 & 0.59 & & & & \\
\hline toaster & 4.39 & 1.04 & 4.18 & 1.14 & 2.83 & 0.86 & 2.81 & 0.88 & 3.79 & 0.92 & 3.79 & 0.94 & 3.50 & 1.10 & 3.51 & 1.08 \\
\hline toilet & 5.00 & 0.00 & 4.91 & 0.55 & 1.61 & 0.92 & 1.63 & 0.70 & 1.32 & 0.95 & 1.34 & 0.88 & & & & \\
\hline toilet paper & 4.56 & 1.15 & 4.84 & 0.69 & 2.17 & 1.29 & 2.04 & 0.93 & 4.79 & 0.42 & 4.86 & 0.40 & 3.42 & 1.22 & 3.23 & 1.23 \\
\hline tomato & 4.17 & 0.92 & 3.71 & 1.30 & 2.44 & 1.04 & 2.37 & 0.84 & 4.89 & 0.46 & 4.81 & 0.58 & 1.84 & 1.12 & 1.80 & 1.03 \\
\hline toothbrush & 4.94 & 0.24 & 4.98 & 0.13 & 2.00 & 1.08 & 1.86 & 1.09 & 5.00 & 0.00 & 4.98 & 0.13 & 2.89 & 1.56 & 2.53 & 1.49 \\
\hline tractor & 1.67 & 0.91 & 1.44 & 0.74 & 2.50 & 1.10 & 2.82 & 1.20 & 1.21 & 0.54 & 1.18 & 0.57 & & & & \\
\hline train & 2.11 & 1.18 & 1.71 & 0.98 & 2.94 & 1.98 & 2.52 & 1.39 & 1.00 & 0.00 & 1.09 & 0.54 & & & & \\
\hline tree & 4.67 & 0.84 & 4.58 & 0.79 & 1.89 & 1.13 & 1.77 & 0.87 & 1.00 & 0.00 & 1.05 & 0.23 & & & & \\
\hline truck & 3.72 & 1.36 & 3.58 & 1.34 & 1.94 & 0.87 & 2.14 & 0.95 & 1.00 & 0.00 & 1.07 & 0.53 & & & & \\
\hline turtle & 1.50 & 0.92 & 1.39 & 0.71 & 2.22 & 0.73 & 2.32 & 0.89 & 2.63 & 1.26 & 2.82 & 1.26 & & & & \\
\hline umbrella & 2.83 & 1.04 & 2.84 & 1.05 & 2.72 & 1.02 & 2.68 & 0.93 & 4.63 & 0.60 & 4.63 & 0.62 & 2.58 & 1.22 & 2.52 & 1.29 \\
\hline vase & 2.50 & 1.38 & 2.13 & 1.09 & 3.39 & 0.85 & 3.44 & 1.00 & 3.79 & 0.79 & 3.84 & 1.05 & 2.00 & 0.91 & 2.24 & 1.26 \\
\hline vest & 2.59 & 1.23 & 2.37 & 1.15 & 3.00 & 1.03 & 2.96 & 0.96 & 4.44 & 0.86 & 4.55 & 0.74 & 3.22 & 1.17 & 3.19 & 1.17 \\
\hline violin & 2.50 & 1.65 & 1.89 & 1.31 & 3.22 & 1.06 & 3.56 & 1.31 & 4.47 & 0.61 & 4.51 & 0.78 & 4.47 & 0.90 & 4.27 & 1.02 \\
\hline wagon & 1.61 & 0.78 & 1.41 & 0.63 & 2.11 & 0.83 & 2.21 & 1.01 & 2.74 & 0.73 & 2.67 & 1.01 & & & & \\
\hline wall (brick) & 4.00 & 1.22 & 4.00 & 1.15 & 3.33 & 1.94 & 2.95 & 1.52 & 1.00 & 0.00 & 1.04 & 0.19 & & & & \\
\hline washing & & & & & & & & & & & & & & & & \\
\hline machine & 3.83 & 1.10 & 3.62 & 1.0 & 3.22 & 1.11 & 3.30 & 0.94 & 1.37 & 1.01 & 1.35 & 0.86 & & & & \\
\hline watch & 4.33 & 1.24 & 4.24 & 1.22 & 3.06 & 1.00 & 2.82 & 0.97 & 4.74 & 0.56 & 4.81 & 0.48 & 3.00 & 1.33 & 3.13 & 1.31 \\
\hline water fountain & 4.06 & 1.30 & 3.72 & 1.28 & 2.89 & 0.68 & 2.93 & 0.68 & 1.32 & 0.95 & 1.42 & 1.10 & & & & \\
\hline well & 1.39 & 0.85 & 1.13 & 0.51 & 2.78 & 0.88 & 3.23 & 1.20 & 1.32 & 0.82 & 1.49 & 1.14 & & & & \\
\hline wheel & 2.44 & 1.58 & 2.44 & 1.52 & 2.72 & 1.07 & 2.72 & 1.06 & 3.32 & 1.11 & 3.37 & 1.22 & 2.53 & 1.19 & 2.82 & 1.30 \\
\hline whistle & 2.28 & 1.27 & 2.07 & 1.30 & 2.94 & 1.16 & 2.81 & 0.93 & 4.95 & 0.23 & 4.95 & 0.23 & 2.47 & 1.26 & 2.44 & 1.34 \\
\hline Wickwire Field* & 4.78 & 0.43 & 4.33 & 1.11 & 3.22 & 1.40 & 3.91 & 1.88 & 1.00 & 0.00 & 1.14 & 0.74 & & & & \\
\hline windmill & 1.67 & 1.08 & 1.36 & 0.78 & 4.00 & 1.33 & 4.12 & 1.30 & 1.16 & 0.50 & 1.14 & 0.61 & & & & \\
\hline wreath & 2.17 & 1.15 & 1.85 & 0.99 & 3.11 & 1.13 & 3.27 & 1.21 & 4.11 & 0.66 & 3.98 & 1.06 & 2.26 & 1.15 & 2.45 & 1.24 \\
\hline wrench & 2.61 & 1.38 & 1.85 & 1.10 & 3.78 & 0.94 & 3.84 & 1.18 & 4.95 & 0.23 & 4.89 & 0.36 & 3.42 & 1.26 & 3.00 & 1.25 \\
\hline yarn & 1.78 & 0.94 & 1.76 & 0.96 & 2.83 & 1.04 & 3.05 & 1.11 & 4.79 & 0.42 & 4.84 & 0.37 & 3.84 & 1.12 & 3.74 & 1.32 \\
\hline zebra & 1.44 & 0.98 & 1.22 & 0.63 & 2.39 & 0.61 & 2.58 & 0.84 & 1.26 & 0.93 & 1.09 & 0.54 & & & & \\
\hline
\end{tabular}

Note-Only Time 1 and overall ratings are provided; for Time 2 and Time 3, please refer to the online supplementary material. AoA, age of acquisition; Manip1, the first manipulation rating scale in the present study, based on the ability to grasp the object; Manip2, the second manipulation rating scale in the present study, based on functional usage. *Halifax-specific locations. 